\title{
Synchronous off-pump coronary artery bypass grafting and carotid endarterectomy (an initial experience)
}

\author{
Abdusalom Abdurakhmanov ${ }^{1}$, Mustapha Obeid ${ }^{1}$, Oybek Mashrapov ${ }^{1}$, Nodirjon Rakhimov ${ }^{1}$ \\ Ulugbek Ganiev², Nodirbek Sultanov ${ }^{3}$, Bakhtiyor Khamidov ${ }^{3}$, Natalia Dadamyantz ${ }^{4}$
}

\footnotetext{
1) Republican Research Center for Emergency Medicine, Cardiac Surgery, Tashkent, Uzbekistan

2) Republican Research Center for Emergency Medicine, Cardiology, Tashkent, Uzbekistan

3) Republican Research Center for Emergency Medicine, Vascular Surgery, Tashkent, Uzbekistan

${ }^{4)}$ Republican Research Center for Emergency Medicine, Radiology and Ultrasound Diagnistics, Tashkent, Uzbekistan
}

\begin{abstract}
Aim: To find out safety and efficacy of synchronous CEA in patients undergoing CABG.

Methods: Out of 711 patients who underwent CABG, 48 were found to have severe carotid stenosis of $>70 \%$. Out of this, 18 patients with $>70 \%$ stenosis (thirteen symptomatic and five asymptomatic) and one patient with $>70 \%$ symptomatic carotid stenosis (TIA within last 2 weeks) were taken for simultaneous CEA along with CABG. These three symptomatic carotid patients suffered from stroke within last 6 months.
\end{abstract}

Results: None suffered from myocardial infarction (MI) during perioperative period.Postoperative recovery period $13,5 \pm 0,8$ days. During the follow-up period of 12 months, one patient died of cardiovascular causes (stroke).

Conclusion: Combined carotid and coronary arteries disease's incidence in this series was $6,3 \%$. Simultaneous carotid and off-pump coronary artery bypass surgery is safe and effective method of treatment patients with severe concomitant carotid artery stenosis and ischemic heart disease with relatively low mortality rate.

Keywords: Carotid endarterectomy, coronary artery bypass graft surgery, off-pump CABG, peri-operative stroke 


\section{Introduction}

Stroke is a serious complication after CABG surgery, occurring in up to $3 \%$ of patients, patients with significant carotid disease represent a particularly high-risk category of patients. ${ }^{[1]}$ Approximately 8-10\% of patients scheduled for coronary artery bypass graft (CABG) surgery, have significant but asymptomatic internal carotid artery (ICA) stenosis. Regarding to the North American Symptomatic Carotid Endarterectomy Trial (NASCET) ${ }^{[2]}$ and Asymptomatic Carotid Atherosclerosis Study (ACAS) ${ }^{[3]}$ carotid endarterectomy (CEA) reduced the risk of stroke in patients with ICA stenosis. During the last decade CEA is increasingly being performed alongside of CABG surgery for stroke prophylaxis. During this procedure cardiac surgeons are aiming to minimize the risk of stroke either by revascularizing the stenotic carotid artery followed by $\mathrm{CABG}$ or in the reversed fashion.

However, some authors consider that the patients who undergo CABG prior to CEA have increased risk of stroke. On the other hand patients undergoing to CEA prior to CABG, have higher risk of myocardial infarction (MI). ${ }^{[4]}$ In order to decrease the rate of mortality and risk of $\mathrm{MI}$ and stroke, performing a CEA and CABG simultaneously (CEA/CABG), can be safe and effective alternative for staged approach. In this study we performed a retrospective analysis of safety and efficacy of CEA combined with CABG in patients with severe carotid stenosis requiring $\mathrm{CABG}$ surgery.

\section{Materials and Methods}

Data of all patients who underwent CABG in our hospital (total 711) from January 2013 to December
2017 were analyzed, of this $45(6,3 \%)$ patients had concomitant carotid and coronary artery stenosis, 18 $(2,5 \%)$ of them needed simultaneous surgery (Picture 1). In recent study only these 18 patients, operated simultaneously were included. Most patients had history of previous myocardial infarction or neurological disorders (patients characteristics are given in Table 1).

Table 1. Demographic and clinical characteristics of patients included in the study

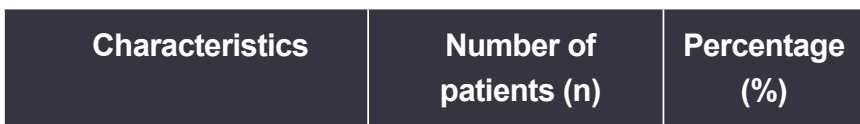

\begin{tabular}{|c|c|c|}
\hline Gender & & \\
\hline Female & 5 & 27.7 \\
\hline Male & 13 & 72.3 \\
\hline $\begin{array}{l}\text { Previous myocar- } \\
\text { dial infarction }\end{array}$ & 13 & 72.3 \\
\hline
\end{tabular}

\section{Neurological history}

\begin{tabular}{|l|c|c|}
\hline Asymptomatic & 5 & 27.7 \\
\hline \multicolumn{1}{|c|}{ Symptomatic } & 13 & 72.3 \\
\hline Hypertension & 12 & 66.6 \\
\hline Smoking & 10 & 55.5 \\
\hline Diabetes mellitus & 12 & 66.6 \\
\hline Hyperlipidaemia & 9 & 50 \\
\hline $\begin{array}{l}\text { Peripheral artery } \\
\text { disease }\end{array}$ & 3 & 16.6 \\
\hline Mean age & $64,8 \pm 1,9$ years & \\
\hline
\end{tabular}

Picture 1. The description of the design of the study (explained in the text).

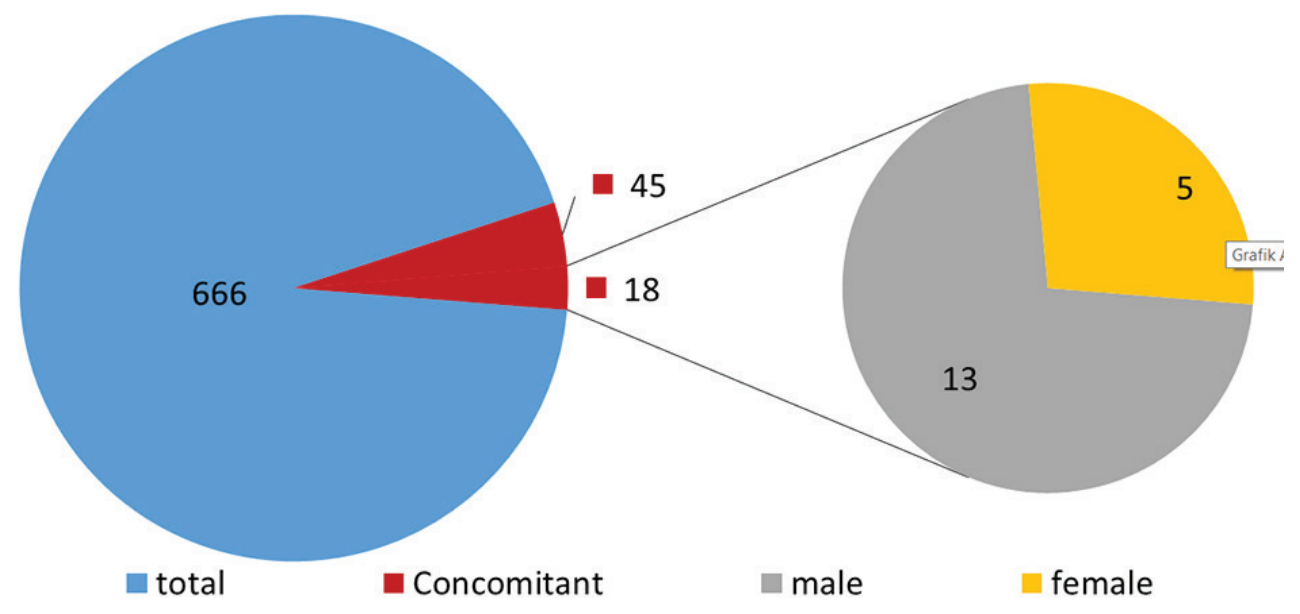

E Journal of Cardiovascular Medicine | Volume 06 | Issue 2 | 2018 
To assess the degree of stenosis of ICAs, carotid Doppler was done preoperatively in all patients. Computed tomography angiogram (CTA) or magnetic resonance angiogram (MRA) was done to confirm the degree of stenosis in patients who had $50 \%$ or more stenosis of carotid artery on carotid Doppler.

Carotid stenosis was defined as severe if stenosis was $>70 \%$ and symptomatic if there was any history of stroke or transient ischemic attack (TIA) within last 6 months involving same side. Near total occlusion was defined as severe stenosis of $>95 \%$ with distal collapse of vessel. The main indications for simultaneous surgery were the need for myocardial revascularization with concomitant 1 . More than $70 \%$ symptomatic stenosis of the carotid artery (with or without contralateral disease) or asymptomatic more than $70 \%$ bilateral carotid artery stenosis.

The eligibility for CEA along with CABG or isolated CABG was determined based on the joint decision of the cardiologist, cardiac surgeon, and neurologist. Patient with intracranial stenosis that exceeded the severity of the extracranial stenosis were excluded. Patients with total occlusion of internal carotid were also excluded. (characteristics of patients regarding to coronary and carotid artery stenoses described in Table 2-3).

All patients underwent carotid artery ultrasonography, coronary angiography, and neurological examination prior to surgery. In 45 of cases $(6,3 \%)$ the concomitant carotid artery stenosis was diagnosed. Simultaneous intervention on the carotid and coronary arterial systems was performed in 18 patients $(2,5 \%)$. The

Table 2. Characteristics coronary artery disease

\begin{tabular}{|l|c|}
\hline \multicolumn{1}{|c|}{$\begin{array}{c}\text { Patientscharacteristics, } \\
\text { coronaryartery }\end{array}$} & Abs.(\%) \\
\hline Triple-vessel disease & $15(83,3 \%)$ \\
\hline Double vessel disease & $1(5,6 \%)$ \\
\hline Left main stem stenosis & $2(11,1 \%)$ \\
\hline $\begin{array}{l}\text { Reduced ejection fraction } \\
\text { (lower than 40\%). }\end{array}$ & $9(50 \%)$ \\
\hline Previous myocardial infarction & $13(72,2 \%)$ \\
\hline Unstableangina. & $10(55,6 \%)$ \\
\hline
\end{tabular}

CEA was done prior to the median sternotomy and after harvesting the conduits; off-pump CABG was followed thereafter. CEA was performed by a vertical incision anterior to the sternocleidomastoid muscle, thus exposing the common carotid artery, ICA, and the external carotid artery. The patient was heparinized by giving 2 $\mathrm{mg} / \mathrm{kg}$ heparin. The artery was opened through a longitudinal incision followed by an endarterectomy. The arteriotomy was closed either directly or by a saphenous vein patch (Picture 2).

Care was taken to keep the systolic blood pressure above $120 \mathrm{mmHg}$ and, inotropic agents were started if needed to maintain adequate blood pressure and cerebral flow. The neck wound was closed with a drain, followed by the median sternotomy, systemic heparinization and a off-pump coronary artery bypass grafting $(17 / 94,4 \%)$, in one case $(5,6 \%)$ due to unstable hemodynamics, the coronary artery bypass was performed on-pump. A stabilization systems were used for mechanical stabilization of the heart while performing all distal anastomosis. Intracoronary shunts were used in most of the patients (Picture 3) to maintain blood flow through the coronary arteries, at the end of procedure heparin was reversed by protamine.

\section{Results}

In our center, all postoperative $\mathrm{CABG}$ patients undergo continuous cardiac monitoring for the first 2 postoperative days. A 12-lead electrocardiogram is also done daily for first 3 days after surgery in all patients. None suffered from perioperative ischemic stroke, but one patient with near total occlusion (asymptomatic)

Table 3. Characteristics of carotid artery disease

\begin{tabular}{|l|c|}
\hline \multicolumn{1}{|c|}{$\begin{array}{c}\text { Patientscharacteristics, } \\
\text { carotidartery }\end{array}$} & Abs.(\%) \\
\hline $\begin{array}{l}\text { Internal carotid artery stenosis on } \\
\text { the right side }\end{array}$ & $5(27,8 \%)$ \\
\hline $\begin{array}{l}\text { Internal carotid artery stenosis on } \\
\text { the left side }\end{array}$ & $6(33,3 \%)$ \\
\hline Bilateral carotid stenosis & $7(38,9 \%)$ \\
\hline Previous stroke & $13(72,2 \%)$ \\
\hline Asymptomatic & $5(27,8 \%)$ \\
\hline
\end{tabular}


suffered from hemorrhagic stroke on ipsilateral side following CEA. All the patients were followed-up till discharge from the hospital. None had any cardiovascular or cerebrovascular complication during this period. There were no any deaths from cardiovascular or any other cause. CT was done in three patients, who had delirium in the early postoperative period, and it did not reveal any fresh ischemic infarction. Their delirium was attributable to perioperative encephalopathy (pain, intensive care unit (ICU) setting). All the patients were discharged from the hospital in stable condition without any fresh neurological deficits (Table 4). Patient with perioperative hemorrhagic stroke following CEA also recovered well (mRS 0-1) at the end of 1 month.

Picture 2. After CEA.arteriotomy was closed by a saphenous vein patch

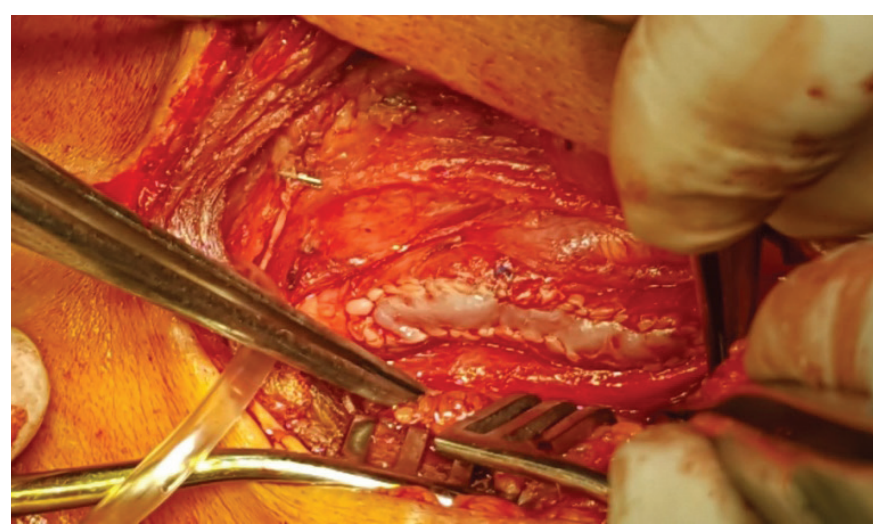

\section{Discussion}

The prevalence of haemodynamically significant $(>50 \%)$ or severe carotid disease $(>80 \%)$, in patients with severe coronary artery disease (CAD) scheduled for $\mathrm{CABG}$ has been estimated to be around $6-17 \%$. ${ }^{[1,2,3]}$ Regarding to a systematic review, the risk of stroke after CABG was $<2 \%$ in patients with no significant carotid disease, $3 \%$ in asymptomatic patients with $50-99 \%$ stenosis, increasing to $5 \%$ in those with bilateral $50-99 \%$ stenosis and $7-11 \%$ in patients with carotid occlusion. ${ }^{[8,12]}$ Moreover, the risk of perioperative stroke in CABG patients suffered from previous TIA or stroke has been associated with a fourfold increased risk as compared to the risk for asymptomatic patients. ${ }^{[9,10]}$ In our series

Table 4. Postoperative period, complications

\begin{tabular}{|l|c|}
\hline \multicolumn{1}{|c|}{ Patients characteristics, } & Abs.(\%) \\
\hline Intracranial hemorrhage* & $1(5,6 \%)$ \\
\hline Reversible cerebral disorder (delirium) & $3(16,7 \%)$ \\
\hline Ischemic stroke & $0(0 \%)$ \\
\hline Mortality rate & $0(0 \%)$ \\
\hline $\begin{array}{l}\text { Cerebral disorder during } 6 \text { month } \\
\text { follow-up }\end{array}$ & $0(0 \%)$ \\
\hline *after 1 month patient suffered ICH showed full recovery \\
\hline
\end{tabular}

Picture 3. Off-pump coronary artery bypass grafting. Heart stabilization during CABG. Intracoronary shunt.
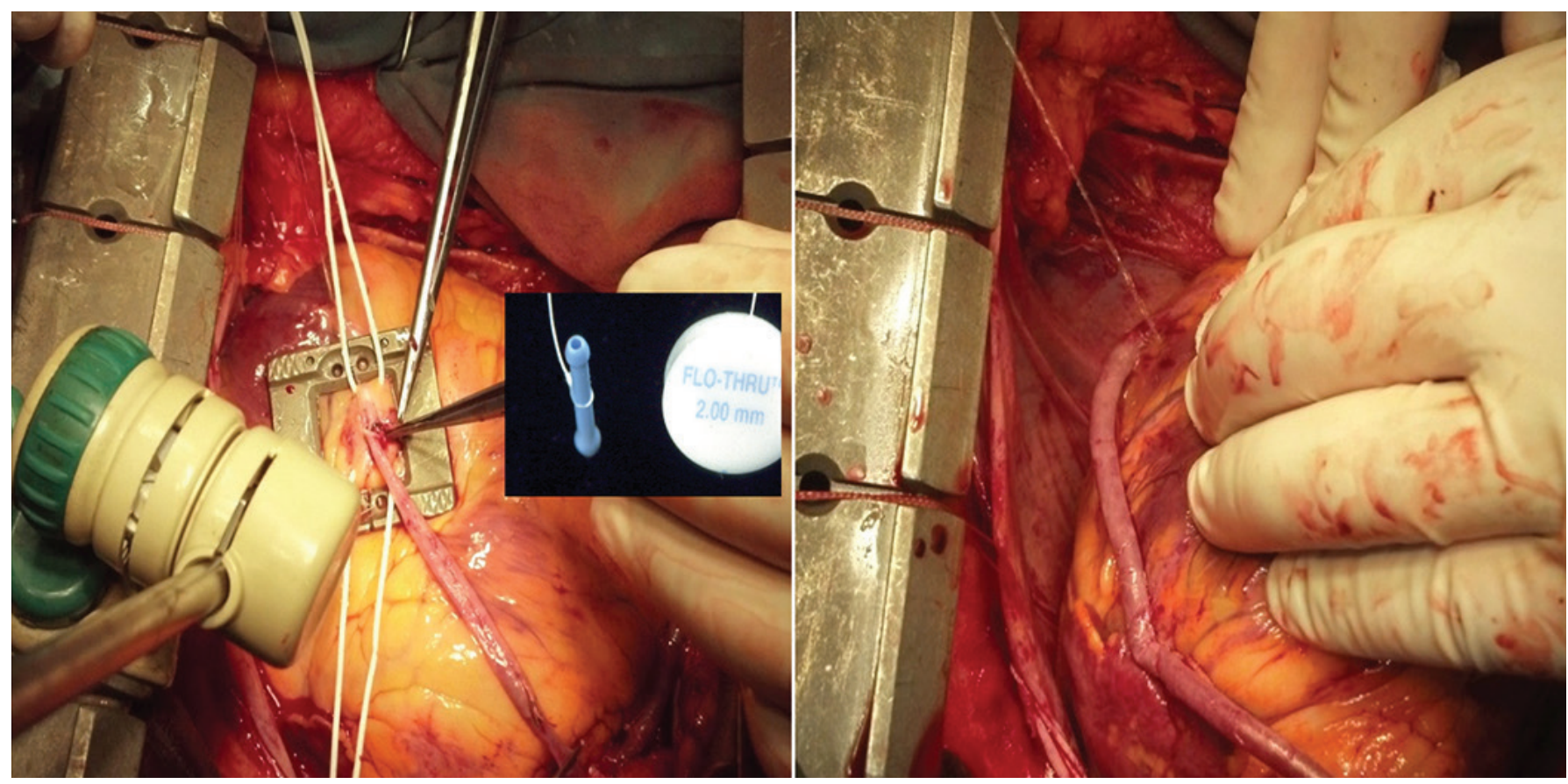
the overall incidence of combined carotid and coronary artery stenosis was $6 \%$. Carotid endarterectomy (CEA) has been well studied in the setting of both symptomatic (North American Symptomatic Carotid Endarterectomy Trial and European Carotid Surgery Trial) as well as asymptomatic (Asymptomatic Carotid Atherosclerosis Study and Asymptomatic Carotid Surgery Trial) individuals with isolated severe carotid disease. ${ }^{[5,6]}$

Nowadays CEA is routinely performed in the setting of CABG surgery in an attempt to improve perioperative outcomes. The operative strategies for combined severe carotid and coronary disease include: (1) CEA followed by CABG (staged); (2) combined CEA and CABG; and (3) CABG followed by CEA (reverse staged). ${ }^{[4,9,10]} \mathrm{But}$ there are still lack of data regarding to evaluating the safety and efficacy of CEA-CABG procedures. AHA recommends that for patients with a TIA or ischemic stroke within the past 6 months and ipsilateral severe (70-99\%) CAS as documented by noninvasive imaging (CD, CTA, and MRA), CEA should be done, if the perioperative morbidity and mortality risk is estimated to be less than $6 \% \cdot{ }^{[14,16]}$ All our patients were admitted primarily for symptomatic $\mathrm{CAD}$ and were planned for CABG based on joint decision of cardiologists and cardiothoracic surgeon.

Carotid Doppler was done as a part of routine screening in all these patients, which revealed carotid stenosis in 45 patients. Decision to do CEA along with CABG was done in 18 eligible patients on the basis of CTA findings. The combination of carotid Doppler and CTA is an acceptable method for the quantification of severe CAS in a substantial number of patients. ${ }^{[15]}$ Decision was based on clinical data; 18 patients scheduled for CABG with concomitant 1 . More than $70 \%$ symptomatic stenosis of the carotid artery (with or without contralateral disease) or asymptomatic more than $70 \%$ bilateral carotid artery stenosis, underwent to simultaneous CEA and CABG.

A recent RCT showed that patients undergoing prophylactic or simultaneous CEA + CABG had low stroke rates $(0 \%)$, without significant perioperative mortality. Overall risk of all types of cerebrovascular complications (stroke, MI, and death) was low during and early after combined CEA + CABG. ${ }^{[11,12,13]}$ Out of 18 patients opted for combined approach, none suffered from ischemic stroke after surgery. Only one patient with near total occlusion had ipsilateral ICH because of hyperperfusion syndrome. A rapid restoration of normal perfusion pressure following CEA may result in hyperperfusion in regions of the brain that have impaired autoregulatory capacity. ${ }^{[18]}$

Risk factors for this syndrome include long-standing hypertension and high-grade stenosis. This patient suffered from faciobrachial paresis, and made almost complete recovery within 1 month. Because carotid revascularization has proven its value in preventing risk of future ischemic stroke in patients with severe carotid disease, it seems appropriate to correct it in conjunction with $\mathrm{CABG}$ to achieve any additional protection from perioperative stroke that this approach may provide. Synchronous CEA/CABG also offers the economic benefit of avoiding two separate procedures/hospitalizations and advantage of patients being exposed to only one anesthesia. ${ }^{[19]}$

\section{Conclusion}

Combined carotid and coronary arteries disease's incidence in this series was $6,3 \%$. Simultaneous carotid and off-pump coronary artery bypass surgery is safe and effective method of treating patients with severe concomitant carotid artery stenosis and ischemic heart disease with relatively low mortality rate. 


\section{References}

1. Ricotta JJ, Faggioli GL, Castilone A, et al . Risk factors for stroke after cardiac surgery: Buffalo Cardiac-Cerebral Study Group. J Vasc Surg 1995;21:359-63; discussion 364.

2. Berens ES, Kouchoukos NT, Murphy SF, et al . Preoperative carotid artery screening in elderly patients undergoing cardiac surgery. J Vasc Surg 1992;15:313-21; discussion 322-3.

3. Salasidis GC, Latter DA, Steinmetz OK, et al . Carotid artery duplex scanning in preoperative assessment for coronary artery revascularization: the association between peripheral vascular disease, carotid artery stenosis, and stroke. J Vasc Surg1995;21:154-60; discussion 161-2.

4. Rajamani K, Chaturvedi S. Surgery Insight: Carotid endarterectomywhich patients to treat and when? Nat ClinPractCardiovasc Med. 2007;4:621-9.

5. Ferguson GG, Eliasziw M, Barr HW, Clagett GP, Barnes RW, Wallace MC, et al. The North American Symptomatic Carotid Endarterectomy Trial: Surgical results in 1415 patients. Stroke. 1999;30:1751-8.

6. Endarterectomy for asymptomatic carotid artery stenosis. Executive Committee for the Asymptomatic Carotid Atherosclerosis Study. JAMA. 1995;273:1421-8.

7. Ricotta JJ, Char DJ, Cuadra SA, Bilfinger TV, Wall LP, Giron F, et al. Modeling stroke risk after coronary artery bypass and combined coronary artery bypass and carotid endarterectomy. Stroke. 2003;5:1212-7.

8. Naylor AR, Mehta Z, Rothwell PM, Bell PR. Carotid artery disease and stroke during coronary artery bypass: A critical review of the literature. Eur J VascEndovasc Surg. 2002;23:283-94.

9. Naylor AR, Cuffe RL, Rothwell PM, Bell PR. A systematic review of outcomes following staged and synchronous carotid endarterectomy and coronary artery bypass. Eur J VascEndovasc Surg. 2003;25:380-9.

10. Manabe S, Shimokava T, Fukui T, Fumimoto KU, Ozawa N, Seki H, et al. Influence of carotid artery stenosis on stroke in patients undergoing off-pump coronary artery bypass grafting. Eur J Cardiothorac Surg. 2008;34:1005-8.

11. Kassaian SE, Abbasi K, HakkiKazazi E, Soltanzadeh A, Alidoosti M, Karimi A, et al. Staged carotid artery stenting and coronary artery bypass surgery versus isolated coronary artery bypass surgery in concomitant coronary and carotid disease. J Invasive Cardiol. 2013;25:8-12

12. Van der Heyden J, Plokker HW. Part Two: Against the motion. Carotid disease is responsible for the increased risk of stroke after coronary bypass surgery. Eur J VascEndovasc Surg. 2010;40:693-

13. Poredos P, Jezovnick MK. Treatment of carotid stenosis before coronary surgery. EJ CardiolPract. 2009:7

14. Illuminati G, Ricco JB, Calio F, Pacile MA, Miraldi F, Frati G, et al. Short term results of a randomized examining timing of carotid endarterectomy in patients with severe asymptomatic unilateral carotid stenosis undergoing coronary artery bypass grafting. J Vasc Surg. 2011;54:993-9.

15. Kernan WN, Ovbiagele B, Black HR, Bravata DM, Chimowitz MI, Ezekowitz MD, et al. Guidelines for the prevention of stroke in patients with stroke and transient ischemic attack: A guideline for healthcare professionals from the American Heart Association/American Stroke Association. Stroke. 2014;45:2160-236.

16. Herzig R, Burval S, Krupka B, Vlachová I, Urbánek K, Mares J. Comparison of ultrasonography, CT angiography, and digital subtraction angiography in severe carotid stenoses. Eur J Neurol. 2004;11:774-81.

17. Brott TG, Halperin JL, Abbara S, Bacharach JM, Barr JD, Bush RL. Guideline on the management of patients with extracranial carotid and vertebral artery disease: Executive summary: A report of the ACC Foundation/American Heart Association Task Force on Practice Guidelines. Catheter CardiovascInterv. 2013;81:E76-123.

18. Halliday A, Mansfield A, Marro J, Peto C, Peto R, Potter J, et al. Prevention of disabling and fatal stroke by successful carotid endarterectomy in patients without recent neurological symptoms: Randomized controlled trial. Lancet. 2004;363:1491-502.

19. Komoribayashi N, Ogasawara K, Kobayashi M, Saitoh H, Terasaki K, Inoue $\mathrm{T}$, et al. Cerebral hyperperfusion after carotid endarterectomy is associated with preoperative hemodynamic impairment and intraoperative cerebral ischemia. Cereb Blood Flow Metab. 2006;26:878-84.

20. Liapis CD, Bell PR, Mikhailidis D, Sivenius J, Nicolaides A, Fernandes $\mathrm{J}$, et al. ESVS Guidelines Collaborators. ESVS Guidelines. Invasive treatment for carotid stenosis: Indications, techniques. Eur J VascEndovasc Surg. 2009;37:1-19.

Received: 25/04/2018

Accepted: 25/05/2018

Published: 05/06/2018

Disclosure and conflicts of interest:

The authors declare no conflict of interest.

Corresponding author:

Abdusalom Abdulagzamovich Abdurakhmanov

Mail: ababdurakhman@gmail.com 